\title{
Teaching-Learning-Based Optimization Algorithm for the Combined Dynamic Economic Environmental Dispatch Problem
}

\author{
Badr M. Alshammari \\ College of Engineering \\ University of Ha'il \\ Ha'il, Saudi Arabia
}

\begin{abstract}
The Dynamic Economic Environmental Dispatch Problem (DEEDP) is a major issue in power system control. It aims to find the optimum schedule of the power output of thermal units in order to meet the required load at the lowest cost and emission of harmful gases. Several constraints, such as generation limits, valve point loading effects, prohibited operating zones, and ramp rate limits, can be considered. In this paper, a method based on Teaching-Learning-Based Optimization (TLBO) is proposed for dealing with the DEEDP problem where all aforementioned constraints are considered. To investigate the effectiveness of the proposed method for solving this discontinuous and nonlinear problem, the ten-unit system under four cases is used. The obtained results are compared with those obtained by other metaheuristic techniques. The comparison of the simulation results shows that the proposed technique has good performance.
\end{abstract}

Keywords-dynamic economic environmental dispatch; teaching-learning-based optimization; prohibited operating zones; ramp rate limits

\section{INTRODUCTION}

With the growing demand for electricity and rising fuel prices, electricity companies are constantly working to ensure continuous and reliable electrical power supply to their customers. In order to achieve this, system operators need to constantly adjust the control variables of power networks. This extremely difficult task is performed by the resolution of the Economic Dispatch Problem (EDP), which aims to determine the production levels of all thermal units which guarantee a balance between production and consumption at the lowest cost. Unfortunately, today network loads are dynamic, which means that it is required to plan the generation of units in real time to guarantee continuous power balance. The resolution of such Dynamic EDP problems (DEDP), considers the constraints imposed by generator Ramp-Rate Limits (RRL). Along with DEDP, the emission dispatch problem, which aims to minimize the emissions of fossil fuels, has emerged. The combination of the two problems in one single problem called Dynamic Economic Environmental Dispatch Problem (DEEDP) has become attractive. DEEDP aims to minimize simultaneously the total production cost and the emission of harmful gases. Thus, it can be considered as a multi-objective problem with conflicting objective functions [1]. In the past, several operating constraints have been taken into account in the DEEDP mathematical formulation, such as power balance constraint, Valve-Point Loading Effects (VPLE), Prohibited Operating Zones (POZ), and RRLs. During the past decades, several techniques have been proposed to solve this kind of problems, including linear programming [2], dynamic programming [3], and gradient algorithms [4]. Unfortunately, in these techniques, the cost function has been approximated by quadratic functions and VPLEs have been ignored in the problem formulation. This frequently leads to inexactitude of the optimal solutions. Moreover, those techniques may be trapped in local optima due to the non-convex and nonlinear characteristics of the cost function. In recent years, various meta-heuristic techniques have been suggested in the literature to overcome the limitations of the traditional methods.

In [1], a differential evolution-based technique has been used to solve the DEEDP where a fuzzy-based method has been employed to extract the optimal solution. Authors in [5] utilized the artificial bee colony algorithm to solve the EDP with VPLEs. Unfortunately, the environmental impact of thermal units has not been considered. Particle swarm optimization (PSO) has also been used to solve power dispatch problems [6-8]. Basu [9] has solved the DEEDP by applying the second version of the Non-dominated Sorting Genetic Algorithm (NSGAII) proving that such technique may provide promising results. Another technique based on NGSAII has been developed in [10] to handle the DEEDP incorporating POZ constraints. An optimization method based on Simulated Annealing (SA) algorithm has been implemented in [11] in this regard, the cost function has been approximated by a cubic function and the problem has been converted into monoobjective problem by using price penalty factors. Within this context, other metaheuristic techniques, such as Gravitational Search Algorithm (GSA) [12], Biogeography-Based Optimization (BBO) [13], Bacterial Foraging Algorithm (BFA) [14], and Harmony Search (HS) algorithm [15] have been developed and implemented for various complex dispatch problems. The main advantage of the aforementioned techniques is that they expand the entire search space for the optimal solution to avoid getting trapped in a local optimal. In addition, these techniques are not concerned with the nature and the shape of the objective functions. However, the 
convergence of most of these techniques depends on their parameters and their computational time is quite large.

The Teaching-Learning-Based Optimization (TLBO) algorithm [16] is a powerful algorithm which can provide promising results in single objective and multi-objective optimization. It is a population algorithm inspired from the teacher/learner relationship. The TLBO algorithm is based on two basic methods of learning: (i) through the teacher, known as the teacher phase, and (ii) through interaction with other students, called student phase. In this optimization algorithm, a group of students is considered as a population and the different subjects offered to the students are considered to be the feasible solutions and a student's result is considered to be the value of the fitness function [16]. The best solution in the whole population, which corresponds to the best value of the objective function, is assigned to the teacher. It has been shown that TLBO has the advantage of only requiring a few control parameters, such as the number of students in the class and the number of subjects presented for students, for its operation [17, $18]$.

In this regard, a TLBO-based method is proposed for dealing with the problem of DEEDP. In the DEEDP formulation all operating constraints, such as generation limits, energy balance, VPLEs, RRLs, and POZ constraints are considered. To render the problem more practical, total real power losses are taken into account. To assess the effectiveness of the proposed optimization method, a ten-unit system is employed. The simulation results obtained by the proposed method are compared with other metaheuristic techniques.

\section{MATHEMATICAL FORMULATION OF THE DEEDP}

The DEEDP is a principal problem in power network operation. It aims to determine the optimum allocation of power outputs of all thermal units to minimize simultaneously the total fuel cost and total emission according to the predicted load demands, over entire dispatch periods generally of one hour. Taking VPLEs into account, the total fuel cost can be expressed by:

$$
C_{T}=\sum_{t=1}^{T} \sum_{i=1}^{N} a_{i}+b_{i} P_{i}^{t}+c_{i}\left(P_{i}^{t}\right)^{2}+\left|d_{i} \sin \left\{e_{i}\left(P_{i}^{\min }-P_{i}^{t}\right)\right\}\right|
$$

where $a_{i}, b_{i}, c_{i}, d_{i}$ and $e_{i}$ are the cost coefficients of unit $i$, $P_{i}^{t}$ is the output power in MW of unit $i$ at time $t, T$ is the number of hours, and $N$ is the number of units.

The second objective function considered in this study, which is the total emission of harmful gases, is described as:

$$
E_{T}=\sum_{t=1}^{T} \sum_{i=1}^{N} \alpha_{i}+\beta_{i} P_{i}^{t}+\gamma_{i}\left(P_{i}^{t}\right)^{2}+\eta_{i} \exp \left(\lambda_{i} P_{i}^{t}\right)
$$

where $\alpha_{i}, \beta_{i}, \gamma_{i}, \eta_{i}$ and $\lambda_{i}$ are the emission coefficients.

In this work, the two objective functions are combined in a single objective function by integrating the price penalty factor. The combined function is:

$$
F_{T}=\delta C_{T}+(1-\delta) \lambda E_{T}
$$

where $\delta=\operatorname{rand}(0,1)$ and $\lambda$ is the average of the price penalty factors of all units. The price penalty factor for unit $i$ can be determined as:

$$
\lambda_{i}=\frac{C_{i}^{\max }}{E_{i}^{\max }}
$$

where $C_{i}^{\max }$ and $E_{i}^{\max }$ are the maximum fuel cost and the maximum emission of unit $i$ respectively.

In order to find the optimal Pareto solutions, the objective function $F_{T}$ is minimized for various values of $\delta$ subject to the constraints (5)-(9). Equation (5) describes the power balance constraint where the real power losses $P_{L}^{t}$ at time $t$ are calculated by (10) [19]. As given in (6), the output power of each generator $i$ should be within its lower $P_{i}^{\min }$ and upper $P_{i}^{\text {max }}$ limits. The RRLs of the thermal units are shown in (7) and (8) while POZs constraints are given in (9).

$$
\sum_{i=1}^{N} P_{i}^{t}-P_{D}^{t}-P_{L}^{t}=0, t=1, \ldots, T
$$

where, $P_{D}^{t}$ is the load at time $t$.

$$
\begin{gathered}
P_{i}^{\min } \leq P_{i}^{t} \leq P_{i}^{\max }, i=1, \ldots, N \\
P_{i}^{t-1}-P_{i}^{t} \leq R_{i}^{\text {down }} \\
P_{i}^{t}-P_{i}^{t-1} \leq R_{i}^{\text {up }}
\end{gathered}
$$

where $R_{i}^{\text {down }}$ and $R_{i}^{u p}$ are the down-ramp and up-ramp limits of unit $i$.

$$
P_{i}^{t} \in\left\{\begin{array}{l}
P_{i}^{\min } \leq P_{i}^{t} \leq P_{i, 1}^{\text {down }} \\
P_{i, k-1}^{u p} \leq P_{i}^{t} \leq P_{i, k}^{\text {down }}, k=2, \ldots, z_{i} \\
P_{i, z_{i}}^{u p} \leq P_{i}^{t} \leq P_{i}^{\max }
\end{array}\right.
$$

where $P_{i, k}^{\text {down }}$ and $P_{i, k}^{u p}$ are the down and up bounds of POZ number $k$ and $z_{i}$ is the number of POZ for unit $i$.

$$
P_{L}^{t}=\sum_{i=1}^{N} \sum_{j=1}^{N} P_{i}^{t} B_{i j} P_{j}^{t}+\sum_{i=1}^{N} B_{o i} P_{i}^{t}+B_{o o}
$$

where, $B_{i j}, B_{o i}, B_{o o}$ are the loss coefficients of $B$-loss matrix.

\section{THE TLBO ALGORITHM}

TLBO algorithm, developed in [16], is a population-based optimization algorithm that mimics the teaching and learning phenomenon in a class. It is inspired by the transmission of knowledge from teacher to students and the mutual interaction between classmates. In TLBO algorithm, students in a class 
constitute the population and a student is considered as a feasible solution for the optimization problem. Subjects offered to students constitute the decision variables and student's result is the fitness function evaluated at the feasible solution. TLBO method is divided into two phases which are teacher phase and student phase.

\section{A. Teacher Phase}

In this phase, the teacher is the main interfering where his job is to improve the knowledge level of learners (students) and helps them to get high grades. However, grades or marks of students depend on teaching quality and student's quality. For simulation, consider there are ' $n$ ' subjects offered to $N_{p o p}$ students. Therefore, variable ' $n$ ' is equivalent to the number of problem design variables and $N_{p o p}$ is the population, in TLBO algorithm. Let $M_{j}^{k}$ be the mean result of learners in a particular subject $j$ where $j \in\{1,2, \ldots, m\}$, at the $k$-th teachinglearning cycle $\left(k \in\left\{0,1,2, \ldots, I^{\max }\right\}\right)$. Since the teacher is the most highly learned and experienced person in the class, thus, he is considered the best learner in the entire population or class. Let $X^{k^{*}}$ be the best solution in the entire population at the $k$-th iteration. The difference between the teacher's results and the mean result of students in the $j$-th subject is calculated as [18]:

$$
D_{j}^{k}=r\left(X_{j}^{k^{*}}-T_{F} M_{j}^{k}\right)
$$

where $r \in[0,1]$ is a random number. $T_{F}$ is the teaching factor that is selected randomly from $\{1,2\}$. It is used to choose which value of mean should be changed.

At the $k$-th teaching-learning cycle, the $i$-th feasible solution is updated according to the following expression.

$$
X_{i j, \text { new }}^{k}=X_{i j, \text { old }}^{k}+D_{j}^{k}
$$

If $X_{i j, \text { new }}^{k}$ gives better results compared to $X_{i j, \text { old }}^{k}$, it is accepted, otherwise, it is rejected. All accepted solutions will be used as input for the student phase.

\section{B. Student Phase}

In this phase, students acquire knowledge through mutual interaction. The learning phenomenon is simulated as follows. Two feasible solutions, $X_{u}^{k}$ and $X_{v}^{k}$ with $u \neq v$, are randomly selected from the population. If $X_{u}^{k}$ is better than $X_{v}^{k}$, then update $X_{v}^{k}$ as given in (14) otherwise update $X_{u}^{k}$ as given in (13). If the new solution is better than the old solution, then, the new solution will be accepted in the population and the old solution will be rejected, otherwise the new solution will be rejected and old solution will be kept in the population.

$$
X_{u j, n e w}^{k}=X_{u j}^{k}+r\left(X_{u j}^{k}-X_{v j}^{k}\right)
$$

$$
X_{v j, n e w}^{k}=X_{v j}^{k}+r\left(X_{v j}^{k}-X_{u j}^{k}\right)
$$

The TLBO algorithm's steps are shown in Figure 1.

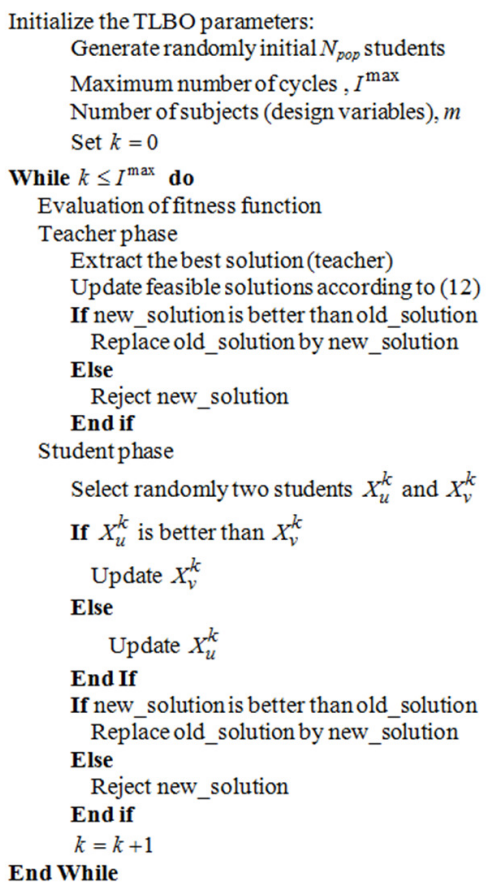

Fig. 1. Steps of the TLBO algorithm.

\section{TLBO ALGORITHM IMPLEMENTATION FOR THE DEEDP}

To verify the effectiveness of the proposed method in solving the DEEDP, numerical experiments are carried out employing the ten unit system. The TLBO algorithm was firstly applied for static economic emission dispatch for total demand power of $P_{D}=2000 \mathrm{MW}$, and then for the dynamic case. All system data are taken from [20]. In this paper, TLBO and PSO algorithms are implemented in Matlab R2018B on a PC intel(R) Core i7, 1.5GHz, 64 bits. Population size and maximum number of iterations are both 200 . The $B$-loss matrix of the studied system is shown in (15).

$B=10^{-4}\left[\begin{array}{llllllllll}0.49 & 0.14 & 0.15 & 0.15 & 0.16 & 0.17 & 0.17 & 0.18 & 0.19 & 0.20 \\ 0.14 & 0.45 & 0.16 & 0.16 & 0.17 & 0.15 & 0.15 & 0.16 & 0.18 & 0.18 \\ 0.15 & 0.16 & 0.39 & 0.10 & 0.12 & 0.12 & 0.14 & 0.14 & 0.16 & 0.16 \\ 0.15 & 0.16 & 0.10 & 0.40 & 0.14 & 0.10 & 0.11 & 0.12 & 0.14 & 0.15 \\ 0.16 & 0.17 & 0.12 & 0.14 & 0.35 & 0.11 & 0.13 & 0.13 & 0.15 & 0.16 \\ 0.17 & 0.15 & 0.12 & 0.10 & 0.11 & 0.36 & 0.12 & 0.12 & 0.14 & 0.15 \\ 0.17 & 0.15 & 0.14 & 0.11 & 0.13 & 0.12 & 0.38 & 0.16 & 0.16 & 0.18 \\ 0.18 & 0.16 & 0.14 & 0.12 & 0.13 & 0.12 & 0.16 & 0.40 & 0.15 & 0.16 \\ 0.19 & 0.18 & 0.16 & 0.14 & 0.15 & 0.14 & 0.16 & 0.15 & 0.42 & 0.19 \\ 0.20 & 0.18 & 0.16 & 0.15 & 0.16 & 0.15 & 0.18 & 0.16 & 0.19 & 0.44\end{array}\right]$

\section{A. Static Dispatch}

The convergence of the objective functions for the proposed algorithm and PSO is shown in Figure 2. It can be seen that TLBO provides cheaper electricity production and lowest emission compared to PSO. In fact, the minimum cost 
and emissions are $132968.93 \$ / \mathrm{h}$ and $18832.63 \mathrm{ton} / \mathrm{h}$ respectively for the TLBO algorithm and $133088.62 \$ / \mathrm{h}$ and 19054.12 ton/h respectively for the PSO algorithm. The Pareto front generated by the proposed algorithm is shown in Figure 3. It is clear that that the Pareto solutions are uniformly distributed in the objective space. Moreover, Figure 3 shows that cost and emissions are conflicting functions.

(a)

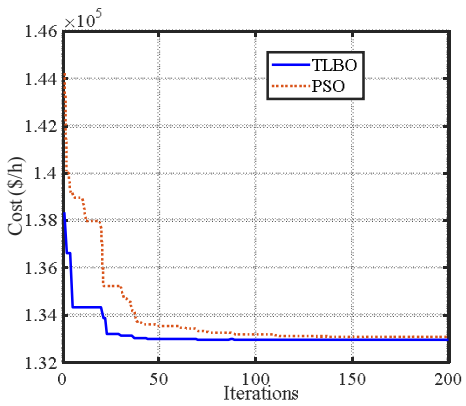

(b)

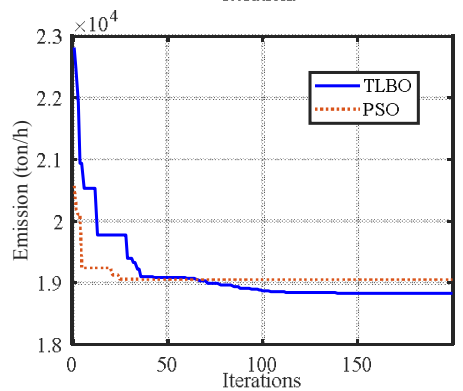

Fig. 2. Convergence of objective functions for $P_{D}=2000 \mathrm{MW}$ : (a) cost, (b) emission

TABLE I. DYNAMIC ECONOMIC DISPATCH

\begin{tabular}{|c|c|c|c|c|c|c|c|c|c|c|c|}
\hline Hour & $P_{D}^{t}$ & $P_{1}$ & $P_{2}$ & $P_{3}$ & $P_{4}$ & $P_{5}$ & $P_{6}$ & $P_{7}$ & $P_{8}$ & $P_{9}$ & $P_{10}$ \\
\hline 1 & 1036 & 150.1259 & 135.5687 & $\begin{array}{l}73.0000 \\
\end{array}$ & 117.0485 & 175.4140 & 126.8733 & 130.0000 & 117.5441 & 20.0000 & 10.0000 \\
\hline 2 & 1110 & 150.0664 & 135.0000 & 73.0000 & 108.9781 & 225.4140 & 160.0000 & 130.0000 & 120.0000 & 20.0000 & 10.0000 \\
\hline 3 & 1258 & 150.2382 & 135.0000 & 153.0000 & 125.7599 & 223.8123 & 159.6342 & 129.5876 & 119.8081 & 49.7545 & 39.8977 \\
\hline 4 & 1406 & 150.5704 & 135.0000 & 206.7431 & 175.7599 & 243.0000 & 159.0079 & 129.5631 & 119.0141 & 79.6457 & 43.2159 \\
\hline 5 & 1480 & 150.5888 & 135.0000 & 255.5104 & 225.7599 & 221.4589 & 156.7358 & 130.0000 & 119.9033 & 78.9610 & 45.4764 \\
\hline 6 & 1628 & 150.2503 & 135.0000 & 335.5104 & 275.7599 & 243.0000 & 159.7044 & 129.6031 & 119.9085 & 79.8822 & 47.4658 \\
\hline 7 & 1702 & 150.1468 & 198.5926 & 331.5975 & 300.0000 & 241.5421 & 160.0000 & 130.0000 & 119.9352 & 79.8647 & 43.3868 \\
\hline 8 & 1776 & 210.1460 & 213.1343 & 340.0000 & 300.0000 & 243.0000 & 160.0000 & 130.0000 & 120.0000 & 80.0000 & 38.2598 \\
\hline 9 & 1924 & 273.4194 & 293.1343 & 340.0000 & 300.0000 & 243.0000 & 160.0000 & 130.0000 & 120.0000 & 80.0000 & 55.0000 \\
\hline 10 & 2022 & 300.4154 & 373.1343 & 340.0000 & 300.0000 & 243.0000 & 160.0000 & 130.0000 & 120.0000 & 80.0000 & 55.0000 \\
\hline 11 & 2106 & 315.4490 & 453.1343 & 337.4498 & 300.0000 & 243.0000 & 160.0000 & 130.0000 & 120.0000 & 80.0000 & 55.0000 \\
\hline 12 & 2150 & 344.5307 & 470.0000 & 340.0000 & 300.0000 & 243.0000 & 160.0000 & 130.0000 & 120.0000 & 80.0000 & 55.0000 \\
\hline 13 & 2072 & 331.2602 & 397.3814 & 340.0000 & 300.0000 & 242.9249 & 159.9539 & 130.0000 & 119.9397 & 79.9670 & 55.0000 \\
\hline 14 & 1924 & 251.3135 & 317.3814 & 338.7426 & 300.0000 & 242.6070 & 159.6948 & 129.9303 & 120.0000 & 79.9776 & 54.9429 \\
\hline 15 & 1776 & 171.7944 & 237.3814 & 339.7179 & 300.0000 & 242.9101 & 159.5908 & 129.9045 & 118.7763 & 79.9693 & 54.4079 \\
\hline 16 & 1554 & 150.0967 & 157.3814 & 296.4912 & 250.7445 & 238.3715 & 159.4043 & 129.3618 & 119.6965 & 53.0343 & 43.1300 \\
\hline 17 & 1480 & 150.9007 & 135.0000 & 240.7998 & 242.3687 & 242.1751 & 159.6100 & 129.7144 & 119.7307 & 55.0000 & 44.0521 \\
\hline 18 & 1628 & 150.3632 & 174.5376 & 300.0000 & 292.3687 & 242.2373 & 159.9336 & 129.4308 & 119.2750 & 54.7366 & 53.3392 \\
\hline 19 & 1776 & 217.4110 & 254.5376 & 300.0000 & 300.0000 & 243.0000 & 160.0000 & 130.0000 & 120.0000 & 55.0000 & 55.0000 \\
\hline 20 & 1972 & 284.3186 & 334.5376 & 340.0000 & 300.0000 & 243.0000 & 160.0000 & 130.0000 & 120.0000 & 80.0000 & 55.0000 \\
\hline 21 & 1924 & 259.9202 & 309.6601 & 340.0000 & 300.0000 & 243.0000 & 159.2709 & 129.8075 & 119.9798 & 79.9277 & 53.0288 \\
\hline 22 & 1628 & 180.1857 & 229.9838 & 291.1958 & 250.6165 & 223.4006 & 159.4022 & 126.6683 & 120.0000 & 51.6945 & 43.7541 \\
\hline 23 & 1332 & 150.2720 & 150.0578 & 211.4456 & 201.6378 & 174.2186 & 160.0000 & 130.0000 & 90.0000 & 52.0055 & 44.2729 \\
\hline 24 & 1184 & 150.5086 & 135.0000 & 131.4456 & 167.0485 & 175.3310 & 110.0000 & 130.0000 & 120.0000 & 50.0000 & 40.0000 \\
\hline Cost (\$) & \multicolumn{11}{|c|}{2472116.66} \\
\hline $\begin{array}{c}\text { Emission } \\
\text { (ton) }\end{array}$ & \multicolumn{11}{|c|}{330411.81} \\
\hline
\end{tabular}


TABLE II. DYNAMIC EMISSION DISPATCH

\begin{tabular}{|c|c|c|c|c|c|c|c|c|c|c|c|}
\hline Hour & $P_{D}^{t}$ & $P_{1}$ & $P_{2}$ & $P_{3}$ & $P_{4}$ & $P_{5}$ & $P_{6}$ & $P_{7}$ & $P_{8}$ & $P_{9}$ & $P_{10}$ \\
\hline 1 & 1036 & 150.3364 & 135.2479 & 88.8628 & 91.5246 & 133.1490 & 133.2677 & 96.0287 & 92.6589 & 79.7478 & 54.8723 \\
\hline 2 & 1110 & 150.4649 & 138.1099 & 101.9172 & 99.8572 & 143.6597 & 143.8590 & 105.5614 & 114.0802 & 79.9698 & 55.0000 \\
\hline 3 & 1258 & 164.2919 & 166.1639 & 117.3305 & 121.6243 & 172.9143 & 159.9093 & 129.7196 & 120.0000 & 80.0000 & 54.9823 \\
\hline 4 & 1406 & 199.0112 & 203.9786 & 147.0126 & 144.0633 & 204.0232 & 159.7183 & 129.9286 & 119.9410 & 79.9646 & 55.0000 \\
\hline 5 & 1480 & 216.9388 & 219.6330 & 157.4592 & 163.6519 & 218.2469 & 160.0000 & 129.9633 & 120.0000 & 79.9462 & 55.0000 \\
\hline 6 & 1628 & 253.4935 & 255.9774 & 190.1283 & 190.7046 & 242.9276 & 159.9049 & 129.9803 & 119.9825 & 80.0000 & 55.0000 \\
\hline 7 & 1702 & 275.2332 & 273.7700 & 209.7002 & 210.7657 & 242.8287 & 160.0000 & 129.9338 & 120.0000 & 79.9196 & 54.9987 \\
\hline 8 & 1776 & 291.1351 & 295.7189 & 229.4559 & 232.4257 & 242.9839 & 159.8865 & 130.0000 & 120.0000 & 80.0000 & 54.8400 \\
\hline 9 & 1924 & 324.3152 & 326.1564 & 277.5305 & 279.7439 & 243.0000 & 160.0000 & 129.9974 & 119.9869 & 79.9975 & 54.9994 \\
\hline 10 & 2022 & 348.6556 & 349.0595 & 321.7455 & 294.5092 & 243.0000 & 160.0000 & 130.0000 & 119.9751 & 80.0000 & 55.0000 \\
\hline 11 & 2106 & 383.1823 & 382.7515 & 339.9697 & 299.9955 & 243.0000 & 160.0000 & 130.0000 & 120.0000 & 80.0000 & 54.9992 \\
\hline 12 & 2150 & 397.8457 & 425.6329 & 340.0000 & 300.0000 & 241.7596 & 152.4816 & 130.0000 & 120.0000 & 80.0000 & 55.0000 \\
\hline 13 & 2072 & 364.1944 & 364.2761 & 339.9983 & 299.9967 & 243.0000 & 159.9968 & 130.0000 & 120.0000 & 79.9960 & 55.0000 \\
\hline 14 & 1924 & 327.2057 & 322.9324 & 278.8479 & 278.7852 & 243.0000 & 159.9789 & 130.0000 & 120.0000 & 79.9829 & 55.0000 \\
\hline 15 & 1776 & 292.5619 & 292.8412 & 230.3221 & 233.2478 & 242.7153 & 159.8868 & 129.8985 & 119.9561 & 80.0000 & 55.0000 \\
\hline 16 & 1554 & 234.6654 & 237.5412 & 181.0347 & 183.2478 & 243.0000 & 160.0000 & 129.7930 & 120.0000 & 55.0000 & 55.0000 \\
\hline 17 & 1480 & 224.4285 & 225.2253 & 162.6887 & 164.5307 & 224.1457 & 160.0000 & 129.9327 & 120.0000 & 54.9989 & 55.0000 \\
\hline 18 & 1628 & 262.2682 & 260.2198 & $\begin{array}{l}197.1840 \\
\end{array}$ & 196.3723 & 242.4237 & 159.9493 & 129.8766 & 119.9320 & 55.0000 & 55.0000 \\
\hline 19 & 1776 & 298.9110 & 296.1538 & 240.5298 & 238.0002 & 243.0000 & 159.9865 & 129.9697 & 120.0000 & 54.9945 & 55.0000 \\
\hline 20 & 1972 & $\begin{array}{l}337.0679 \\
\end{array}$ & 337.4869 & $\begin{array}{l}297.2509 \\
\end{array}$ & 287.9121 & 242.9982 & $\begin{array}{l}159.9977 \\
\end{array}$ & 129.9953 & $\begin{array}{l}119.9968 \\
\end{array}$ & 79.9966 & 54.9965 \\
\hline 21 & 1924 & 328.1016 & 326.5158 & 278.6325 & 274.7016 & 243.0000 & 159.9165 & 130.0000 & 119.9709 & 79.9725 & 54.9936 \\
\hline 22 & 1628 & 248.1062 & 246.5158 & 198.6325 & 224.7016 & 215.3974 & 159.6594 & 130.0000 & 119.9354 & 79.8864 & 55.0000 \\
\hline 23 & 1332 & 176.4330 & 166.5158 & 127.4188 & 174.7016 & 174.6863 & 160.0000 & 129.7901 & 119.8400 & 80.0000 & 54.9865 \\
\hline 24 & 1184 & 154.0152 & 155.7069 & 100.8685 & 124.7016 & 168.9035 & 152.3155 & 107.1434 & 110.9206 & 80.0000 & 55.0000 \\
\hline Cost (\$) & \multicolumn{11}{|c|}{2594148.32} \\
\hline $\begin{array}{c}\text { Emission } \\
\text { (ton) }\end{array}$ & \multicolumn{11}{|c|}{294153.04} \\
\hline
\end{tabular}

TABLE III. COMBINED ECONOMIC EMISSION DISPATCH

\begin{tabular}{|c|c|c|c|c|c|c|c|c|c|c|c|}
\hline Hour & $P_{D}^{t}$ & $P_{1}$ & $P_{2}$ & $P_{3}$ & $P_{4}$ & $P_{5}$ & $P_{6}$ & $P_{7}$ & $P_{8}$ & $P_{9}$ & $P_{10}$ \\
\hline 1 & 1036 & 150.4594 & 135.3072 & 80.0281 & 120.0864 & 126.2070 & 124.4066 & 129.6379 & 86.1200 & 59.2616 & 44.0814 \\
\hline 2 & 1110 & 150.0709 & 135.0000 & 81.2516 & 102.8341 & 167.8358 & 125.3782 & 129.3292 & 116.1200 & 79.9973 & 44.7038 \\
\hline 3 & 1258 & 150.4932 & 135.0161 & 138.7766 & 129.6167 & 188.9086 & 160.0000 & 129.2388 & 120.0000 & 79.7994 & 54.6856 \\
\hline 4 & 1406 & 154.9053 & 161.9512 & 177.1730 & 179.6167 & 223.7618 & 159.9893 & 129.7067 & 119.9437 & 79.9075 & 54.7681 \\
\hline 5 & 1480 & 152.9466 & 217.8705 & 186.4596 & 185.1000 & 236.2579 & 159.5941 & 130.0000 & 119.8567 & 79.8784 & 52.1092 \\
\hline 6 & 1628 & 213.1264 & 236.4829 & 260.3624 & 203.1865 & 243.0000 & 136.3359 & 130.0000 & 120.0000 & 80.0000 & 55.0000 \\
\hline 7 & 1702 & 227.8217 & 221.6160 & 271.7060 & 246.9217 & 243.0000 & 160.0000 & 129.8277 & 120.0000 & 79.9719 & 55.0000 \\
\hline 8 & 1776 & 228.2304 & 242.9587 & 290.8592 & 286.3618 & 242.9531 & 159.9532 & 130.0000 & 119.4716 & 79.8240 & 54.3041 \\
\hline 9 & 1924 & 293.0721 & 293.5529 & 340.0000 & 280.7385 & 243.0000 & 160.0000 & 130.0000 & 120.0000 & 80.0000 & 54.5004 \\
\hline 10 & 2022 & 306.2281 & 368.3049 & 340.0000 & 300.0000 & 243.0000 & 160.0000 & 129.8569 & 120.0000 & 80.0000 & 54.1663 \\
\hline 11 & 2106 & 376.6213 & 389.3073 & 339.9899 & 299.9805 & 242.9987 & 159.9980 & 129.9979 & 119.9977 & 79.9869 & 54.9993 \\
\hline 12 & 2150 & 385.6214 & 428.8158 & 340.0000 & 300.0000 & 243.0000 & 160.0000 & 130.0000 & 120.0000 & 80.0000 & 55.0000 \\
\hline 13 & 2072 & 361.8808 & 397.2726 & 340.0000 & 300.0000 & 243.0000 & 160.0000 & 130.0000 & 90.0000 & 80.0000 & 55.0000 \\
\hline 14 & 1924 & 289.4585 & 317.2726 & 300.7884 & 300.0000 & 243.0000 & 159.9907 & 129.6966 & 119.8300 & 80.0000 & 55.0000 \\
\hline 15 & 1776 & 232.8384 & 281.4039 & 276.1673 & 257.2175 & 242.9575 & 159.8950 & 129.9781 & 120.0000 & 79.9478 & 55.0000 \\
\hline 16 & 1554 & 153.0008 & 218.8426 & 222.2456 & 241.2300 & 243.0000 & 159.9386 & 130.0000 & 119.8715 & 55.0000 & 55.0000 \\
\hline 17 & 1480 & 150.1175 & 217.9193 & 195.6985 & 194.4730 & 243.0000 & 159.8241 & 129.9954 & 119.9426 & 55.0000 & 54.0499 \\
\hline 18 & 1628 & 229.1932 & 233.6730 & 207.0696 & 244.4730 & 243.0000 & 160.0000 & 130.0000 & 120.0000 & 55.0000 & 55.0000 \\
\hline 19 & 1776 & 257.6630 & 290.2181 & 268.7446 & 256.2676 & 242.9809 & 159.9782 & 130.0000 & 120.0000 & 54.9739 & 54.9997 \\
\hline 20 & 1972 & 271.6633 & 347.2125 & 340.0000 & 300.0000 & 243.0000 & 160.0000 & 130.0000 & 120.0000 & 80.0000 & 55.0000 \\
\hline 21 & 1924 & 301.8759 & 308.5015 & 297.6986 & 299.7156 & 242.8737 & 159.9440 & 129.6663 & 119.8831 & 79.9622 & 54.9860 \\
\hline 22 & 1628 & 222.0018 & 228.5015 & 217.6986 & 249.7616 & 222.5752 & 159.8970 & 129.6350 & 119.9210 & 79.9730 & 47.2841 \\
\hline 23 & 1332 & 150.2022 & 148.5746 & 138.5624 & 200.3815 & 223.2994 & 159.5506 & 130.0000 & 89.9210 & 80.0000 & 43.5042 \\
\hline 24 & 1184 & 150.4527 & 135.1441 & 73.0000 & 170.0864 & 173.2994 & 127.6795 & 130.0000 & 114.8581 & 80.0000 & 55.0000 \\
\hline Cost (\$) & \multicolumn{11}{|c|}{2519909.93} \\
\hline $\begin{array}{c}\text { Emission } \\
\text { (ton) }\end{array}$ & \multicolumn{11}{|c|}{303338.20} \\
\hline
\end{tabular}

Table III depicts the best compromise solution obtained from the resolution of the combined DEEDP. Fuzzy-based method [9] is employed to extract the optimal best compromise solutions. The total cost is $2519909.93 \$$ which is more than the cost obtained for the pure economic dispatch $(2472116.66 \$)$ and less than the cost obtained for the pure environmental dispatch (2594148.32\$). Similarly, the emission is 303338.20ton which is less than the emission obtained for the 
pure economic dispatch (330411.81ton) and more than the emission obtained for the pure environmental dispatch. The comparison results shown in Table IV show that the proposed TLBO outperforms PSO, Improved Bacterial Foraging Algorithm (IBFA), and the second version of the Nondominated Sorting Genetic Algorithm (NSGAII) in finding the optimum generation schedule for the DEEDP.

TABLE IV. COMPARISON WITH OTHER META-HEURISTIC TECHNIQUES

\begin{tabular}{|c|c|c|}
\hline Method & Minimum cost (\$) & Minimum emission (ton) \\
\hline TLBO & 2472116.66 & 294153.04 \\
\hline PSO & 2497562.38 & 301539.82 \\
\hline IBFA [21] & 2481733.3 & 295833.0 \\
\hline NSGAII [10] & $2.5168 \times 10^{6}$ & $3.1740 \times 10^{5}$ \\
\hline
\end{tabular}

\section{CONCLUSION}

In this study, a new metaheuristic called TeachingLearning-Based Optimization (TLBO) algorithm was used for solving the DEEDP. The problem is described as an optimization problem. The decision variables of the problem are the output powers of units at the hours of a single day. Energy balance equation, generation limits, valve point loading effects, prohibited operating zones and ramp rate limits are considered as problem constraints. To assess the effectiveness of the proposed method, the ten-unit system is used. The TLBO is applied for the pure dynamic economic dispatch, the pure dynamic environmental dispatch and the combined dynamic economic environmental dispatch. The obtained results were compared with other techniques proposed recently in the literature, such as PSO, IBFA and NSGAII, and it was found that the proposed algorithm outperforms them.

\section{REFERENCES}

[1] X. Jiang, J. Zhou, H. Wang, and Y. Zhang, "Dynamic environmental economic dispatch using multiobjective differential evolution algorithm with expanded double selection and adaptive random restart," International Journal of Electrical Power \& Energy Systems, vol. 49, pp. 399-407, Jul. 2013, https://doi.org/10.1016/j.ijepes.2013.01.009.

[2] G. W. Chang et al., "Experiences with mixed integer linear programming based approaches on short-term hydro scheduling," IEEE Transactions on Power Systems, vol. 16, no. 4, pp. 743-749, Nov. 2001, https://doi.org/10.1109/59.962421.

[3] Z.- Liang and J. D. Glover, “A zoom feature for a dynamic programming solution to economic dispatch including transmission losses," IEEE Transactions on Power Systems, vol. 7, no. 2, pp. 544-550, May 1992, https://doi.org/10.1109/59.141757.

[4] C. Cao, J. Xie, D. Yue, J. Zhao, Y. Xiao, and L. Wang, "A distributed gradient algorithm based economic dispatch strategy for virtual power plant," in 2016 35th Chinese Control Conference (CCC), Chengdu, China, Jul. 2016, pp. 7826-7831, https://doi.org/ 10.1109/ChiCC.2016.7554598.

[5] Y. Labbi, D. B. Attous, and B. Mahdad, "Artificial bee colony optimization for economic dispatch with valve point effect," Frontiers in Energy, vol. 8, no. 4, pp. 449-458, Dec. 2014, https://doi.org/ 10.1007/s11708-014-0316-8.

[6] J. B. Park, K. S. Lee, J. R. Shin, and K. Y. Lee, "A particle swarm optimization for economic dispatch with nonsmooth cost functions," IEEE Transactions on Power Systems, vol. 20, no. 1, pp. 34-42, Feb. 2005, https://doi.org/10.1109/TPWRS.2004.831275.

[7] N. Singh and Y. Kumar, "Economic load dispatch with environmental emission using MRPSO," in 2013 3rd IEEE International Advance Computing Conference (IACC), Ghaziabad, India, Feb. 2013, pp. 995999, https://doi.org/10.1109/IAdCC.2013.6514362.
[8] W. Jiang, Z. Yan, and Z. Hu, "A Novel Improved Particle Swarm Optimization Approach for Dynamic Economic Dispatch Incorporating Wind Power," Electric Power Components and Systems, vol. 39, no. 5, pp. 461-477, Mar. 2011, https://doi.org/10.1080/15325008.2010. 5628536.

[9] A. Torchani, A. Boudjemline, H. Gasmi, Y. Bouazzi, and T. Guesmi, "Dynamic Economic/Environmental Dispatch Problem Considering Prohibited Operating Zones," Engineering, Technology \& Applied Science Research, vol. 9, no. 5, pp. 4586-4590, Oct. 2019, https://doi.org/10.48084/etasr.2904.

[10] M. Basu, "Dynamic economic emission dispatch using nondominated sorting genetic algorithm-II," International Journal of Electrical Power \& Energy Systems, vol. 30, no. 2, pp. 140-149, Feb. 2008, https://doi.org/10.1016/j.ijepes.2007.06.009.

[11] I. Ziane, F. Benhamida, and A. Graa, "Simulated annealing algorithm for combined economic and emission power dispatch using $\max / \max$ price penalty factor," Neural Computing and Applications, vol. 28, no. 1, pp. 197-205, Dec. 2017, https://doi.org/10.1007/s00521-016-2335-3.

[12] I. Bala and A. Yadav, "Optimal Reactive Power Dispatch Using Gravitational Search Algorithm to Solve IEEE-14 Bus System,” in Communication and Intelligent Systems, Singapore, 2020, pp. 463-473, https://doi.org/10.1007/978-981-15-3325-9 36.

[13] V. Raviprabhakaran and C. S. Ravichandran, "Enriched BiogeographyBased Optimization Algorithm to Solve Economic Power Dispatch Problem," in Proceedings of Fifth International Conference on Soft Computing for Problem Solving, Singapore, 2016, pp. 875-888, https://doi.org/10.1007/978-981-10-0451-3_78.

[14] B. Hernández-Ocaña, J. Hernández-Torruco, O. Chávez-Bosquez, M. B. Calva-Yáñez, and E. A. Portilla-Flores, "Bacterial Foraging-Based Algorithm for Optimizing the Power Generation of an Isolated Microgrid," Applied Sciences, vol. 9, no. 6, p. 1261, Jan. 2019, https://doi.org/10.3390/app9061261.

[15] K. Lenin, B. R. Reddy, and M. Suryakalavathi, "Upgraded Harmony Search Algorithm for Solving Optimal Reactive Power Dispatch Problem," International Journal of Mathematics Research, vol. 4, no. 1, pp. 42-52, 2015.

[16] R. V. Rao, V. J. Savsani, and D. P. Vakharia, "Teaching-learning-based optimization: A novel method for constrained mechanical design optimization problems," Computer-Aided Design, vol. 43, no. 3, pp. 303-315, Mar. 2011, https://doi.org/10.1016/j.cad.2010.12.015.

[17] A. Farah, T. Guesmi, H. Hadj Abdallah, and A. Ouali, "A novel chaotic teaching-learning-based optimization algorithm for multi-machine power system stabilizers design problem," International Journal of Electrical Power \& Energy Systems, vol. 77, pp. 197-209, May 2016, https://doi.org/10.1016/j.ijepes.2015.11.050.

[18] H. Singh Gill, B. Singh Khehra, A. Singh, and L. Kaur, "Teachinglearning-based optimization algorithm to minimize cross entropy for Selecting multilevel threshold values," Egyptian Informatics Journal, vol. 20, no. 1, pp. 11-25, Mar. 2019, doi: 10.1016/j.eij.2018.03.006.

[19] T. M. Kumar and N. A. Singh, "Environmental Economic Dispatch with the use of Particle Swarm Optimization Technique based on Space Reduction Strategy," Engineering, Technology \& Applied Science Research, vol. 9, no. 5, pp. 4605-4611, Oct. 2019, https://doi.org/ 10.48084/etasr.2969.

[20] T. Guesmi, A. Farah, I. Marouani, B. Alshammari, and H. H. Abdallah, "Chaotic sine-cosine algorithm for chance-constrained economic emission dispatch problem including wind energy," IET Renewable Power Generation, vol. 14, no. 10, pp. 1808-1821, 2020, https://doi.org/10.1049/iet-rpg.2019.1081.

[21] N. Pandit, A. Tripathi, S. Tapaswi, and M. Pandit, "An improved bacterial foraging algorithm for combined static/dynamic environmental economic dispatch," Applied Soft Computing, vol. 12, no. 11, pp. 35003513, Nov. 2012, https://doi.org/10.1016/j.asoc.2012.06.011. 